\title{
PATTERNS OF MYOINVASION IN ENDOMETRIOID ADENOCARCINOMA OF ENDOMETRIUM
}

\author{
Mehroosh Shakeel, Sajid Mushtaq, Noreen Akhtar, Iftikhar Ali Rana, Raza Muhammad \\ Shaukat Khanum Memorial Cancer Hospital \& Research Centre, Lahore Pakistan
}

\begin{abstract}
Objective: To assess the patterns of myoinvasion of endometrial endometrioid adenocarcinoma, their frequencies in our hospital and to correlate these patterns with survival.

Study Design: Retrospective observational study.

Place and Duration of Study: Department of Pathology, Shaukat Khanum Memorial Cancer Hospital \& Research Centre, Lahore, from Aug 2019 to Apr 2020.

Methodology: All cases of endometrial endometrioid adenocarcinoma between 2015 and 2017 were retrieved from the archives, independently reviewed by two researchers, all key reporting parameters recorded in addition to the pattern of myoinvasion as per their operational definitions described by Cole and Quick. The follow-up of 3-5 years was obtained from archives and through telephonic contact for outside hospital patients. Disease free survival and relapse-associated mortality were represented through Kaplan-Meier curves.

Results: Eighty cases of myoinvasive endometrial endometrioid adenocarcinoma were reviewed. We found that infiltrating irregular gland pattern was the most frequent in all the age groups. Thirty-five $(43.75 \%)$ cases showed this type of invasion, followed by broad front pattern $23(28.75 \%)$, Microcystic Elongated and Fragmented (MELF) pattern 15 (18.75\%) and adenomyotic pattern $6(7.5 \%)$. One case showed a combination of the last two patterns, whereas adenoma malignum pattern was not seen. Follow-up of these patients showed $8(10 \%)$ patients with relapse related mortality including $5(62.5 \%)$ infiltrating irregular glands, 2 (25\%) adenomyosis-like and 1 (12.5\%) broad front pattern of myoinvasion. Seventy-two (90\%) patients had recurrence free survival.

Conclusion: Frequency of infiltrating irregular pattern of myoinvasion in endometrial endometrioid adenocarcinoma is high and associated with recurrence related mortality. Recognition of these patterns is important as their impact on overall management and prognosis is, however, unknown, and further studies are required to determine the importance of these patterns.
\end{abstract}

Keywords: Endometrial carcinoma, Lymphovascular invasion, MELF, Myoinvasive pattern.

How to Cite This Article: Shakeel M, Mushtaq S, Akhtar N, Rana IA, Muhammad R. Patterns of Myoinvasion in Endometrioid Adenocarcinoma of Endometrium. Pak Armed Forces Med J 2021; 71(6): 2211-2215. Doi: https://doi.org/10.51253/pafmj.v71i6.5147

This is an Open Access article distributed under the terms of the Creative Commons Attribution License (https://creativecommons.org/licenses/by-nc/4.0/), which permits unrestricted use, distribution, and reproduction in any medium, provided the original work is properly cited.

\section{INTRODUCTION}

Endometrial cancer is the most common cancer of female genital tract, with endometrioid adenocarcinoma of the endometrium the most common type. ${ }^{1}$

Approximately $75 \%$ of women with endometrial cancer are postmenopausal. Decisions regarding surgical treatment, adjuvant therapy and follow-up of the patient depend on accurate tumor staging and grading. ${ }^{2}$ Traditionally, for this purpose, College of American Pathologists and Royal College of Pathologists have been using tumor type, grade, extent of invasion and lymphovascular invasion in their datasets for reporting cancers. ${ }^{3}$ Extent of invasion is of critical importance in determining the stage and further treatment. Recently many studies have been conducted on the significance of various invasive morphologies within

Correspondence: Dr Mehroosh Shakeel, Department of HistoPathology, SKMCH \& RC Lahore Pakistan

Received: 22 Aug 2020; revision received: 17 Oct 2020; accepted: 19 Oct 2020 the spectrum of endometrioid adenocarcinoma, identifying fewof these as adverse prognostic factors. ${ }^{4,5}$ Five different patterns of myoinvasion have been described such as infiltrating irregular glands, broad front, adenoma malignum, adenomyosis like and Microcystic Elongated and Fragmented (MELF) glands. In broad front pattern, potential pitfall is that it may be misinterpreted as non-myoinvasive. Invasion across a broad front may be difficult to distinguish from an irregular endomyometrial interface unless it can be compared to the adjacent uninvolved endomyomet-rium. MELF merits attention because it is easy to overlook at low magnification yet it may be the only pattern of myoinvasion. It is also associated with lymphovascular invasion and higher probability of nodal metastasis. Awareness of adenoma malignum pattern of myoinvasion is essential from a diagnostic standpoint, because it may be difficult to distinguish from non-invasive cancer in the setting of an undulating endomyometrial 
junction, involvement of stroma-poor adenomyosis or to measure true extent of invasion. These patterns should be recognized to improve staging accuracy, treatment and follow up. ${ }^{6-8}$

The objective of this study was to assess these patterns of myoinvasion and their frequencies in our hospital and to correlate these patterns with survival.

\section{METHODOLOGY}

This retrospective observational study was conducted at the Department of Pathology, Shaukat Khanum Memorial Cancer Hospital \& Research Centre, Lahore, from August 2019 to April 2020. With permission from Institutional Review Board (Letter Number EX-04-10-19-01), 80 females were selected through purposive non-probability sampling.

Inclusion Criteria: Patients, who fulfilled the criteria i.e. primary endometrial endometrioid adenocarcinoma, any FIGO grade, any pT stage, hysterectomy and bilateral salpingo-oophorectomy performed between January 2015 to December 2017 were included in the study.

Exclusion Criteria: Patients with diagnosed serous carcinomas, history of metastasis and pre-surgery therapy were excluded from the study.

The follow-up of 3-5 years was obtained from archives and through telephonic contact for outside hospital patients. All cases were retrieved from the archives and independently reviewed by two researchers. Prognostic factors including FIGO grade, myoinvasion, lymphovascular invasion and tumor stage were assessed from pathological reports and reassessed during evaluation for patterns of myoinvasion. Presence of different morphologic patterns of invasion were noted as per their operational definitions described by Cole and Quick. ${ }^{8}$ Infiltrating, irregular glands are individually dispersed glands or groups of 3 or less, have irregular gland contours, widely scattered throughout the endometrium. Broad front or pushing defined as infiltration marked by large swath of neoplastic glands that appear to push into the underlying myometrium with or without desmoplasia. They may appear noninvasive if not carefully assessed. MELF are neoplastic cells and glands that appear MELF admixed with inflammation and represent deepest extent of invasion. Adenomyotic-like Invasion shows groups of invasive endometrioid adenocarcinoma glands (usually 3 or more) that infiltrate the myometrium in irregular islands. Adenoma malignumis composed of regular and round glands, often widely spaced, invade the my- ometrium with no surrounding desmoplasia response; exceedingly rare and it is deceptively bland and maybe overlooked.

Finally, all the above-mentioned parameters were recorded. pT staging was done according to AJCC guidelines. ${ }^{9}$ Data was entered and analyzed through SPSS version 20 . All the qualitative variables like myoinvasion and patterns of myoinvasion were described by using frequency and percentage. Data were stratified for age, FIGO grade and pT stage and Lymphovascular Invasion (LVI). Disease Free Survival (DFS) and relapse-associated mortality were defined and plotted in Kaplan-Meier curves.

\section{RESULTS}

Eighty myoinvasive endometrial endometrioid adenocarcinoma were reviewed. The mean age of the patients was $58.57 \pm 9.83$ years. Patients in their sixth decade constituted just over half of the study population $(n=41)$ whereas only one patient was younger than 40 years. The frequencies of the patterns of invasion in our cases were as follows (Table-I): infiltrating

\begin{tabular}{|c|c|}
\hline Patterns of Myoinvasion & n (\%) \\
\hline Infiltrating, Irregular Glands & $35(43.75)$ \\
\hline Broad Front/Pushing & $23(28.75)$ \\
\hline $\begin{array}{l}\text { Microcystic elongated and } \\
\text { fragmented pattern }\end{array}$ & 15 (18.75) \\
\hline Adenomyotic-like Invasion & $6(7.55)$ \\
\hline Adenoma Malignum & - \\
\hline $\begin{array}{l}\text { Adenomyotic-like \& Microcystic } \\
\text { elongated and fragmented pattern }\end{array}$ & $1(1.25)$ \\
\hline
\end{tabular}

irregular glands pattern 35 (43.75\%) (Figure-1A), broad front pattern 23 (28.75\%) (Figure-1B), MELF pattern 15 (18.75\%) (Figure-1C) and adenomyosis-like pattern 6 $(7.5 \%)$ (Figure-1D). One case showed a combination of the last two patterns in equal proportion (Figure-1E \& $1 \mathrm{~F})$, whereas adenoma malignum pattern was not seen in any case. Infiltrating irregular glands pattern was the most frequent in all age groups, histological grades and pT stages except in cases of FIGO grade I and pT1a cancers.

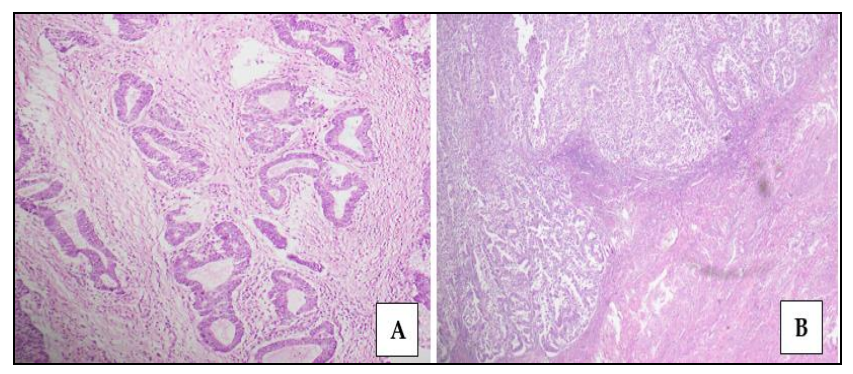




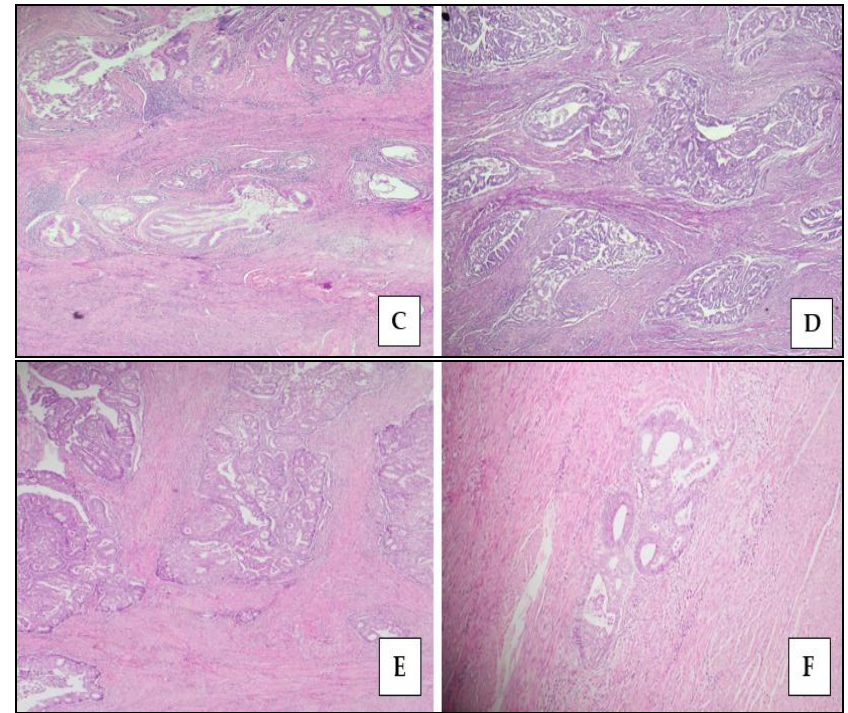

Figure-1(A): Irregular infiltrating irregular glands with no stromal response (B): Broad front myoinvasion (C): Myoinvasion by microcystic elongated glands (MELF) (D): Adenomyosis-like (E\&F): Combination pattern including adenomyosislike \& MELF.

Notably, FIGO grade I and pT1a cancers predominantly showed broad front invasion being 10 $(43.4 \%)$ and $20(86.95 \%)$ respectively. Lymphovascular invasion was noted in 13 cases (16\%) and were mostly limited to cases exhibiting infiltrating irregular glands pattern and MELF pattern (Table-II).
During the follow-up period (35 years), all patients underwent standard hysterectomy with or without bilateral salpingo-oophorectomy. None of them had lymphadenectomy. Thirty four patients $(42.5 \%)$ received radiotherapy and $19(33.8 \%)$ patients $(23.75 \%)$ had only surgery. We could not get data of adjuvant therapy in 27 patients. There were $8(10 \%)$ patients who showed relapse related mortality. Among these patients, $5(62.5 \%)$ had infiltrating irregular glands, $2(25 \%)$ had adenomyosis-like and $1(12.5 \%)$ had broad front pattern of myoinvasion. One patient died of an unknown cause. Seventy two $(90 \%)$ patients had recurrence free survival (Table-III). The disease free-survival rate is shown in Kaplan-Meier curves (Figure-2).

Table-III: Disease free survival based on pattern of myoinvasion.

\begin{tabular}{|c|c|c|}
\hline $\begin{array}{l}\text { Patterns of } \\
\text { Myoinvasion }\end{array}$ & $\begin{array}{c}\text { No. of Deaths } \\
\text { (Relapse Related } \\
\text { Mortality) }\end{array}$ & $\begin{array}{c}\text { Disease Free } \\
\text { Survival } \\
\text { n (\%) } \\
\end{array}$ \\
\hline Infiltrating irregular glands & $5(14.3)$ & $30(85.7)$ \\
\hline Broad Front & $1(4.3)$ & $22(95.7)$ \\
\hline $\begin{array}{l}\text { Microcystic elongated and } \\
\text { fragmented pattern }+ \\
\text { Adenomyosis-like \& } \\
\text { Microcystic elongated and } \\
\text { fragmented pattern }\end{array}$ & - & $16(100)$ \\
\hline Adenomyosis-like & $2(33.3)$ & $4(66.7)$ \\
\hline Overall & $8(10.0)$ & $72(90)$ \\
\hline
\end{tabular}

Table-II: Pathological characteristic of study population.

\begin{tabular}{|c|c|c|c|c|c|c|}
\hline Variable & $\begin{array}{c}\text { Infiltrating } \\
\text { Irregular Glands, } \\
\mathbf{n = 3 5}(\%)\end{array}$ & $\begin{array}{c}\text { Broad Front } \\
n=23(\%)\end{array}$ & $\begin{array}{c}\text { Microcystic } \\
\text { Elongated and } \\
\text { Fragmented Pattern } \\
\text { (MELF), } \mathrm{n}=\mathbf{1 5}(\%)\end{array}$ & $\begin{array}{c}\text { Adenomyosis- } \\
\text { Like } \\
n=6(\%)\end{array}$ & \begin{tabular}{|c|} 
Adenomyosis-like and \\
Microcystic Elongated \\
and Fragmented \\
Pattern, $n=1(\%)$
\end{tabular} & $\begin{array}{c}p- \\
\text { value }\end{array}$ \\
\hline \multicolumn{7}{|l|}{ Age (years) } \\
\hline $31-40$ & $1(2.85)$ & - & - & - & - & \multirow{5}{*}{0.001} \\
\hline $41-50$ & $6(17.14)$ & $5(21.73)$ & $1(6.67)$ & $2(33.34)$ & - & \\
\hline $51-60$ & $18(51.42)$ & $12(52.1)$ & 7 (46.67) & $3(50)$ & $1(100)$ & \\
\hline $61-70$ & $7(20)$ & $4(17.39)$ & $5(33.34)$ & - & - & \\
\hline $71-80$ & $3(8.57)$ & $2(8.69)$ & $2(13.34)$ & $1(16.67)$ & - & \\
\hline \multicolumn{7}{|c|}{ International Federation of Gynecology and Obstetrics (FIGO) Grade } \\
\hline Grade-I & $8(22.85)$ & $10(43.47)$ & $4(26.66)$ & $4(66.66)$ & - & \multirow{3}{*}{0.030} \\
\hline Grade-II & $19((54.28)$ & $9(39.13)$ & $11(73.33)$ & $2(33.33)$ & - & \\
\hline Grade-III & $8(22.85)$ & $4(17.39)$ & - & - & $1(100)$ & \\
\hline \multicolumn{7}{|c|}{ Primary Tumor(pT) Stage } \\
\hline pT1 & $28(80)$ & $20(86.95)$ & $15(100)$ & $6(100)$ & - & \multirow{4}{*}{0.303} \\
\hline pT2 & $3(8.57)$ & $3(13.04)$ & - & - & $1(100)$ & \\
\hline pT3 & $4(11.2)$ & - & - & - & - & \\
\hline pT4 & - & - & - & - & - & \\
\hline \multicolumn{7}{|c|}{ Lymphovascular Invasion (LVI) } \\
\hline Present & $5(14.24)$ & - & 7 & - & $1(100)$ & 0.002 \\
\hline \multicolumn{7}{|c|}{ Lymphovascular Invasion (LVI) } \\
\hline Absent & $30(85.71)$ & $23(100)$ & $8((22.85)$ & $6(100)$ & - & \\
\hline
\end{tabular}




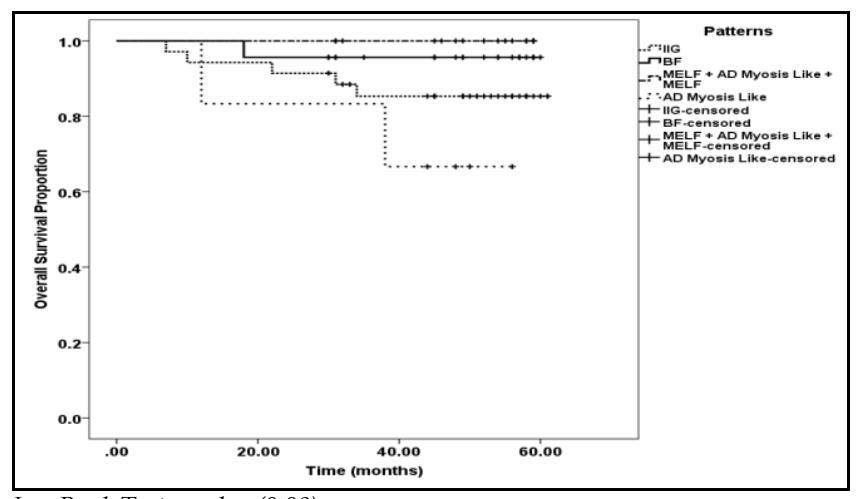

Log Rank Test p-value (0.09)

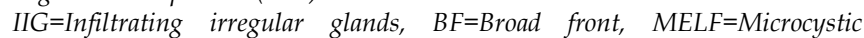
elongated and fragmented pattern, $A D$ myosis $=$ Adenomyosis-like

Figure-2: Kaplan-Meier curves showing disease free survival of our pattern of myoinvasion.

\section{DISCUSSION}

Cole and Quick first described patterns of myoinvasion in endometrial endometrioid adenocarcinoma in 2013. ${ }^{8}$ Recognition of these patterns is linked with adverse prognostic features. In broad front pattern, potential pitfall is that it may be misinterpreted as nonmyoinvasive. Moreover, there is a study by Caracuel et al. which showed an independent association of broad front pattern with tumor relapse in early stage, low grade EEC. ${ }^{10}$ MELF merits attention because it is easy to overlook at low magnification yet it may be the only pattern of myoinvasion present and it is easy to misinterpret as lymphovascular invasion or adenomyosis. It is commonly associated with lympho-vascular invasion and high nodal metastasis. ${ }^{11}$ Adenoma malignum pattern of myoinvasion merits awareness from a diagnostic standpoint because it may be difficult to distinguish may lead to more accurate staging, but perhaps more importantly, some patterns may be associated from non-invasive cancer in the setting of an undulating endomyometrial junction, to distinguish from involvement of stroma-poor adenomyosis or to measure true depth of invasion. 12,13

In our study, the most common pattern was of infiltrative irregular glands pattern of myoinvasion i.e. $43.75 \%$. In a study by Price et al, observed infiltrative invasion pattern in $47.8 \%$, MELF in $12.9 \%$, pushing borders of invasion in $2.8 \%$, adenomyosis-like invasion in $1.1 \%$ and adenoma malignum-like invasion in $0.2 \%$ patients with endometrioid adenocarcinomas. ${ }^{14} \mathrm{We}$ found this pattern in all age groups, FIGO grade I/II cancers and pT stages except pT1a. Lymphovascular invasion (LVI) was found in 5/35 cases. On follow-up, this pattern showed $85.7 \%$ overall survival rate and 5 $(62.5 \%)$ disease related deaths. Similarly, Park et al, and his colleagues also showed an association between this pattern and disease recurrence, however, their series included grade III high-staged tumors. ${ }^{15}$

The second common pattern of invasion in our study was broad front pattern, seen in $28.75 \%$ cases (Table-I), common in the age group of 51-60 years. In a study conducted by Quick et al, broad front pattern was seen in $21 \%$ of the tumors. ${ }^{16}$ This pattern was more commonly observed in low-grade low-stage tumors ( $43.47 \%$ in FIGO grade I \& $86.95 \%$ in pT1 stage) and no LVI observed. Our 3-5 year follow up study depicted a very good disease free survival rate of $95.7 \%$ and only $1(12.5 \%)$ had disease related death. On the contrary, Caracuel and his colleagues found significant tumor relapse associated with this pattern of myoinvasion in early stage. ${ }^{10}$

MELF pattern of invasion was seen in 15 patients $(18.75 \%)$ and 1 case showed mixed adenomyosis-like and MELF patterns in equal proportions, whereas, larger cases are also reported in many other studies including a study by Espinosa et al, (43\% MELF pattern) 17 and a study by Hertel et al, (36\% MELF cases). ${ }^{18}$ This pattern commonly shows lymphovascular invasion and lymph node metastasis. ${ }^{19}$ Not only this, MELF pattern has also been reported with extrauterine disease. ${ }^{20}$ We observed LVI in 7 out of 15 of our MELF cases. Despite its association with LVI that is considered bad prognostic factor, interestingly, we found $100 \%$ survival rate in this pattern as well as the combined pattern with adenomyosis-like. No disease-relapse was identified (Figure-6). Similarly, Kihara et al also demonstrated no significant worsening of prognosis with MELF pattern. ${ }^{21}$

In our study, we described that apart from MELF association with LVI, it has no worse impact on outcome. Likewise, broadfront pattern of invasion also showed good disease-free survival rate. As a result, the on the other side, our strength included strict morphological criteria used to determine frequencies of patterns of myoinvasion and positive impact of some patterns in our setup. Hence, further studies should be done to work on the importance of myoinvasion patterns and its outcome.

\section{LIMITATION OF STUDY}

There were, however, many limitations acknowledged in this study including relative low number of tumor relapses, different surgical protocols used by different surgeons, non-availability of adjuvant therapy and patients lost on follow-ups.

\section{CONCLUSION}

This study concluded that frequency of infiltrating irregular pattern of myoinvasion in endometrial endometrioid adenocarci- 
noma is high among patients in our study group and has association with recurrence related mortality. Some of the patterns of myoinvasion are associated with good outcome despite the lymphovascular invasion. Identification of each pattern promotes understanding of the unique challenges associated with each, especially with regard to assessing for depth of invasion, extent of tumor spread, lymphovascular invasion and nodal involvement.

\section{Conflict of Interest: None.}

\section{Authors' Contribution}

MS: Acquisition of data, interpretation of results and writing, SM: Concept, design, review of the case and proof reading, NA: Review of the cases, interpretation and proof reading, UH: Proof reading, IAR: Proof reading, RM: Proof reading, concept and writing.

\section{REFERENCES}

1. Khazaei Z, Hasanpour D, Amiri M, Adineh H. The incidence and mortality of endometrial cancer and its association with body mass index and human development index in Asian population. World Cancer Res J 2018; 5(4): e117.

2. Endometrial Cancer Stage. www.cancer.org. 2020 Available at: https://www.cancer.org/cancer/endometrial-cancer/detectiondiagnosis-staging/staging.html [Accessed on September 28, 2020].

3. Ganesan R, Singh N, McCluggage WG. Standards and datasets for reporting cancers: Dataset for histological reporting of endometrial cancer. Royal College of Pathologists. Available at: https://www.rcpath.org/uploads/assets/124ed697f77149d0856958f1a0ae3ed9/30243a46-9850-41dd91001b8e58369b2a/G090-Dataset-for-the-histopathologicalreporting-of-endometrial-cancer-For-publication [Accessed on September 28, 2020].

4. Helpman L, Kupets R, Covens A, Saad RS, Khalifa MA, Ismiil N, et al. Assessment of endometrial sampling as a predictor of final surgical pathology in endometrial cancer. Br J Cancer 2014; 110(3): 609.

5. Barlin J, Lutz M, Zhou Q, Clair CS, Leitao M, Iasonos A, et al. Redefining stage I endometrial cancer: Incorporating histology, grade, myoinvasion, and whether or not lymph nodes were removed. Gynecol Oncol 2013; 130(1): e74-e78.

6. Soslow R. Practical issues related to uterine pathology: staging, frozen section, artifacts, and Lynch syndrome. Mod Pathol 2016; 29(S1): S59-S77.

7. McCluggage W. Selected areas of difficulty in staging of endometrial carcinomas. USCAP. 2017 [Internet] Available at: https://handouts.uscap.org/AN2017/2017_CM19_mcclu_0401. pdf. [Accessed on September 28, 2020].

8. Cole AJ, Quick CM. Patterns of myoinvasion in endometrial adenocarcinoma: recognition and implications. Adv Anat Pthol 2013; 20(3): 141-147.

9. Olawaiye $\mathrm{AB}$, Mutch DG. Lymphnode staging update in the American Joint Committee on Cancer 8th Edition cancer staging manual. Gynecol Oncol 2018; 150(1): 7-8.
10. Ruz-Caracuel I, Ramón-Patino J, López-Janeiro Á, Yébenes L, Berjón A, Hernández A. Myoinvasive pattern as a prognostic marker in low-grade, early-stage endometrioid endometrial carcinoma. Cancers 2019; 11(12): 1845.

11. Dogan AM, Kir G, Topal C, Cetiner H, Gocmen A. The association of the microcystic, elongated and fragmented (MELF) invasion pattern in endometrial carcinomas with deep myometrial invasion, lymphovascular space invasion and lymph node metastasis. J Obstet Gynaecol 2014; 35(4): 397-402.

12. Deb PQ, Marcus JZ, Abedin Y, Heller DS. A Deceptive spread: myoinvasion of endometrial carcinoma imitating adenoma malignum. Int J Surg Pathol 2020; 28(3): 284-286.

13. Tanvir I, Riaz S, Hussain A, Mehboob R, Shams MU, Khan HA. Hospital-based study of epithelial malignancies of endometrial cancer frequency in Lahore, Pakistan, and common diagnostic pitfalls. Pathol ResInt 2014, Available at: https:// www.hindawi. com/journals/pri/2014/179384/ [Accessed on Sep 28, 2020].

14. Joehlin-Price AS, Stephens JA, Zhang J, Backes FJ, Cohn DE, Suarez AA. Endometrial cancer insulin-like growth factor 1 receptor (IGF1R) expression increases with body mass index and is associated with pathologic extent and prognosis. Cancer Epidemiol Biomarkers Prev 2016; 25(3): 438-445.

15. Park J, Hong D, Park J. Association between morphological patterns of myometrial invasion and cancer stem cell markers in endometrial endometrioid carcinoma. Pathol Oncol Res 2017; 25(1): 123-130.

16. Quick CM, May T, Horowitz NS, Nucci MR. Low-grade, lowstage endometrioid endometrial adenocarcinoma: a clinicopathologic analysis of 324 cases focusing on frequency and pattern of myoinvasion. Gynecol Pathol 2012; 31(4): 337-343.

17. Espinosa I, Serrat N, Zannoni G, Rovira R, D'Angelo E, Prat J. Endometrioid endometrial carcinomas with microcystic, elongated, and fragmented (MELF) type of myoinvasion: role of immunohistochemistry in the detection of occult lymph node metastases and their clinical significance. Hum Pathol 2017; 70(1): 6-13.

18. Hertel JD, Huettner PC, Pfeifer JD. Lymphovascular space invasion in microcystic elongated and fragmented (MELF)-pattern well-differentiated endometrioid adenocarcinoma is associated with a higher rate of lymph node metastasis. Int J Gynecol Pathol 2014; 33(2): 127-134.

19. Joehlin-Price A, McHugh K, Stephens J, Li Z, Backes F, Cohn D, et al. The microcystic, elongated, and fragmented (MELF) pattern of invasion: a single institution report of 464 consecutive FIGO grade 1 endometrial endometrioid adenocarcinomas. Am J Surg Pathol 2017; 41(1): 49-55.

20. Euscher E, Fox P, Bassett R, Al-Ghawi H, Ali-Fehmi R, Barbuto $\mathrm{D}$, et al. The pattern of myometrial invasion as a predictor of lymph node metastasis or extrauterine disease in low-grade endometrial carcinoma. Am J Surgical Pathol 2013; 37(11): 17281736.

21. Kihara A, Yoshida H, Watanabe R, Takahashi K, Kato T, Ino $Y$, et al. Clinicopathologic association and prognostic value of microcystic, elongated, and fragmented (melf) pattern in endometrial endometrioid carcinoma. Am J Surg Pathol 2017; 41(7): 896-905. 